\title{
IPTEKS PERATURAN PERPAJAKAN, KUALITAS PELAYANAN, DAN SANKSI PERPAJAKAN TERHADAP KEPATUHAN WAJIB PAJAK KENDARAAN BERMOTOR PADA BADAN PENGELOLAH PAJAK DAN RETRIBUSI DAERAH PROVINSI SULAWESI UTARA
}

\author{
Harianti H. Basri ${ }^{1}$, Sonny Pangerapan ${ }^{2}$ \\ 1,2,Jurusan Akuntansi, Fakultas Ekonomi dan Bisnis, Universitas Sam Ratulangi, Jl. Kampus Bahu, Kota Manado, \\ 95115, Indonesia \\ E-mail : hariantibasri18@gmail.com
}

\begin{abstract}
Taxes are main source state revenues where state activities such as national development financed from taxes are implement the. This study aims know application knowledge, technology about tax regulations, service quality, and tax sanctions to taxpayers, service quality has a positive effect, Compliance with taxpayers in paying greatly determines effectiveness Motor Vehicle Tax collection, regulations, service quality sanctions influence motor vehicle taxpayer registered in Badan Pengelolah Pajak dan Retribusi Daerah Provinsi Sulawesi Utara.
\end{abstract}

Keywords : Vehicle tax, Tax sanctions, Service Quality and Tax Compliance

\section{PENDAHULUAN}

Pajak adalah iuran yang dibayar masyarakat yang ditujukan untuk Negara dapat dipaksakan berdasarkan peraturan yang ditetapkan tanpa jasa timbal, dan bukan digunakan untuk kepentingan pribadi tapi digunakan untuk kepentingan pemerintah dan masyarakat umum. Kepatuhan wajib pajak yaitu dimana wajib pajak memenuhi semua kewajiban perpajakannya atas hak yang dia dapat. Badan Pengelolah Pajak dan Retribusi Daerah Prov. Sulut beroperasi dibidang pajak daerah. Salah satu tugasnya merealisasikan target pendapatan asli daerah yaitu target pajak kendaraan bermotor.

\section{TINJAUAN PUSTAKA}

Pajak adalah pungutuan terahadap rakyat untuk Negara yang terutang berdasarkan peraturan undang-undang dengan sifat memaksa dan tidak mendapat imbalan secara langsung dari Negara guna untuk membiayai pengeluaran pemerintah dan pembangunan (Siahaan, 2013:7). Kendaraan bermotor adalah jenis kendaraan bermotor yang beroda dengan digerakkan pada peralatan teknik berupa motor dan lainya yang fungsinya merubah sumber daya energi sehingga dapat menjadi tenaga gerak yang digunakan diseluruh jalan darat dan juga kendaraan bermotor yang diopersikan di air. Pajak kendaraan bermotor merupakan pemungutan atas kepemilikan atau penguasaan kendaraan bermotor baik itu roda dua atau lebih. Kualitas pelayanan merupakan sebagai ukuran kemampuan dari aparat pajak dalam memberikan sikap yang hormat dan memberikan informasi yang lebih jelas secara lengkap kepada wajib pajak sehingga dapat dimengerti dan pelayanan yang memuaskan kepada wajib pajak. kualitas pelayanan pajak berpengaruh positif tetapi tidak terdukung. Sanksi perpajakan merupakan pencegahan agar wajib pajak dapat mentaati dan tidak melanggar ketentuan undang-undang yang berlaku, dengan adanya sanksi pajak ini merupakan jeminan untuk Wajib pajak agar tidak melalaikan kewajibannya, dan wajib pajak akan patuh dalam membayar pajak karena memikirkan adanya sanksi yang berat. 


\section{METODE DAN TEKNIK PENERAPAN IPTEKS}

\subsection{Metode Penerapan Ipteks}

Metode ipteks yang diterapkan adalah studi kasus atas hasil penelitian saya tentang kualitas pelayanan terhadap wajib pajak.

\subsection{Teknis penerapan Ipteks}

Berdasarkan hasil penelitian harianti (2018), maka teknik ipteks yang diterapkan yaitu kualitas pelayanan, official assessment system yang meliputi: menentukan besarnya pajak terutang terhadap pemerintah, wajib pajak yang bersifat pasif, dikeluarkan surat ketetapan pajak yang menimbulkan utang pajak yaitu melalui unit pelayanan.

\section{PEMBAHASAN}

\subsection{Gambaran Objek Penerapan Ipteks}

Hasil penelitian menunjukan bahwa Badan Pengelolah Pajak dan Retribusi Daerah Provinsi Sulawesi Utara adalah instansi pemerintah yang bergerak dibidang pajak. Badan Pengelolah Pajak dan Retribusi Daerah berkedudukan di Manado tepatnya di Jln. 17 Agustus No. 67, Kota Manado, Provinsi Sulawesi Utara. Dan juga mempunyai tugas dalam membantu gubernur untuk melaksanakan penyusunan dan pelaksanaan kebijakan daerah dalam pengelolaan pajak dan retribusi daerah.

\subsection{Pembahasan}

Untuk penyediaan sarana dan prasarana BP2RD Provinsi Sulawesi Utara mengembangkan sistem yang berbasis teknologi, dan melakukan penambahan unit pelayanan. Sementara itu, sosialisasi dilakukan kepada masyarakat sampai titik desa. Itu adalah strategi dari BP2RD Provinsi Sulawesi Utara. Sosialisasi dilakukan dalam banyak bentuk, ada yang langsung pada masyarakat, lewat media dan dunia maya, brosur di unit-unit pelayanan dan lain-lain. Cara untuk mengetahui efektivitas sebuah pemungutan pajak. Penerimaan Pajak Kendaraan Bermotor dapat dilihat dari indikator antara target yang ditetapkan dengan realisasi yang dicapai dalam sebuah periode tertentu. Melalui indikatorindikator tersebut maka efektivitas dalam pemungutan Pajak Kendaraan Bermotor dapat terlihat Dalam meningkatkan penerimaan melalui pemungutan Pajak Kendaraan Bermotor, maka Badan Pengelolah Pajak dan Retribusi Daerah Prov. Sulut telah membuat sebuah strategi dalam upaya merealisasikan target yang telah ditetapkan sebelumnya. Realisasi pendapatan pajak daerah yang dikelolah Badan Pendapatan Daerah Provinsi Sulawesi Utara dengan 3 maret 2018 sebesar $\mathrm{Rp}$ 164.729.951.126 dari target tahun 2018 sebesar $\mathrm{Rp}$ 1.000.049.416.000 atau 16,47\%. Dilihat dari target triwulan I sebesar 15\%, maka target telah tercapai, sedangkan target harian sampai dengan 3 maret 2018 sebesar Rp 176.675.396.827 belum mencapai Rp 11.945.445.701. -16\%. Salah satu rinciannya yaitu pajak kendaraan bermotor ditargetkan sebesar Rp 318.136.824.684, realisasi Rp 58.821.387.407 atau 18,49\%, untuk target harian sampai dengan 3 maret 2018 sebesar Rp 56.204.172.361 melampaui sebesar Rp 204.172.046 atau 4,66\%. Berikut rincian target dan realisasi pajak daerah: 
Tabel 1. Target pendapatan daerah pada Badan Pengelolah Pajak dan Retribusi Daerah Provinsi Sulawesi Utara

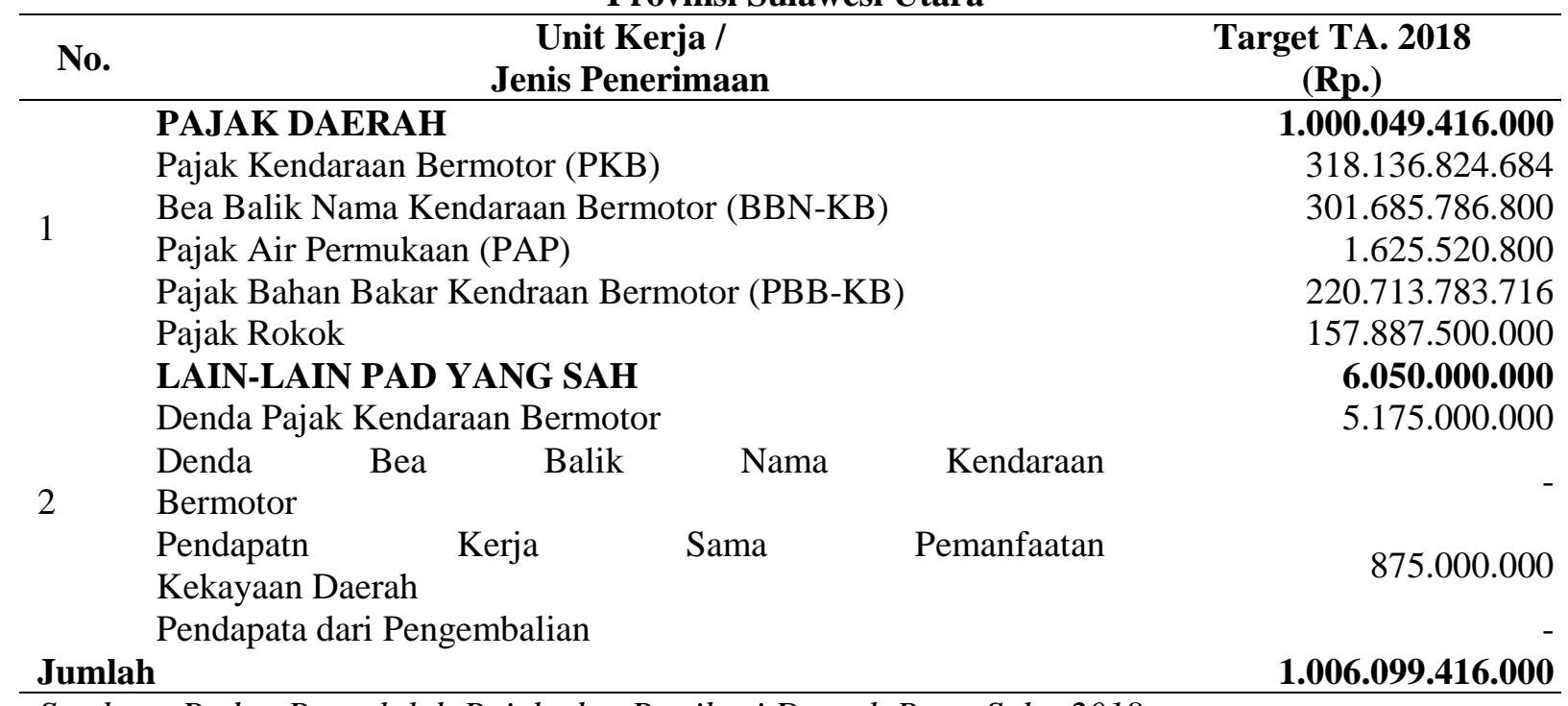

Sumber : Badan Pengelolah Pajak dan Retribusi Daerah Prov. Sulut 2018

Kepatuhan dari wajib pajak dalam membayar sangat menentukan efektivitas pemungutan Pajak Kendaraan Bermotor. Indikator pajak serta pembayaran pajak sebelum jatuh tempo. Melalui indikator-indikator tersebut maka efektivitas dalam pemungutan Pajak Kendaraan Bermotor dapat terlihat. Terdapat beberapa alasan dari wajib pajak yang patuh dalam membayar Pajak Kendaraan Bermotor. Untuk menghindari denda dan menghindari operasi tilang ketika dalam melakukan perjalanan dengan menggunakan kendaraan bermotor.

\section{KESIMPULAN DAN SARAN}

\subsection{Kesimpulan}

Target kendaraan bermotor sangat berpengaruh terhadap target pendapatan daerah maka Badan Pengelolah Pajak dan Rteribusi Daerah Prov. Sulut memberikan pelayanan yang baik terhadap wajib, apabila wajib pajak tidak membayar pajak maka akan dikenakan sanksi berdasarkan undang-undang yang berlaku.

\subsection{Saran}

Badan Pengelolah Pajak dan Retribusi Daerah Provinsi Sulawesi Utara terus pengembangkan dan juga lebih meningkatkan pelayanan yang diberikan terhadap wajib pajak, dan juga Meningkatkan kesadaran wajib pajak dengan cara meningkatkan citra pemerintah dengan terbuka terhadap penggunaan uang pajak sehingga wajib pajak memiliki kepercayaan kepada pemerintah.

\section{DAFTAR PUSTAKA}

Ilyas, B.W dan R. Burton. 2010. Hukum Pajak. Selemba Empat. Jakarta

Ilhamsyah, randy. (2016). Pengaruh pemahaman Dan Pengetahuan Wajib Pajak Tetang peraturan Perpajakan, Kesadaran Wajib Pajak, Kualitas Pelayanan, dan Sanksi Perpajakan Terhadap Kepatuhan Wajib Pajak. Jurnal Perpajakan, 8(1), 2-3.

Istanto, Fery. (2010). Analisis Pengaruh Pengetahuan Tentang Pajak, Kualitas Pelayanan Pajak, Ketegasan Sanksi Perpajakan, dan Tingkat Pendidikan Terhadap Motivasi Wajib Pajak dalam Membayar Pajak, Skripsi Strata-1. Jakarta: Fakultas Ekonomi dan Bisnis UIN Syarif Hidayatullah 
Jatmiko, Agus Nugroho. (2006). "Pengaruh sikap wajib pajak pada pelaksanaan sanksi denda, pelayanan fiskus, dan kesadaran perpajakan terhadap kepatuhan wajib pajak". Tesis. Semarang: Program Studi Magister Akuntansi Pasca Sarjanan Universitas Diponegoro.

Mardiasmo, 2011. Perpajakan,Edisi Revisi. Andi Offset. Yogyakarta

Muljono, Djoko. 2010. Hukum Pajak. Andi Offset. Yogyakarta

Mardiasmo, 2009. Perpajakan, Edisi Revisi. Andi Offset. Yogyakarta

Ritnawati, Juli. 2015. Dasar-Dasar Perpajakan, Budi Utama. Yogyakarta

Rochmat soemitro, 2003. Asas Dasar Pajak dan Dasar Perpajakan, Jakarta: IKAPI.

Siahaan, Marihot Pahala. 2013. Edisi Revisi Pajak Daerah \& Retribusi Daerah. Rajawali Pers. Jakarta

Waluyo, 2011. Perpajakan Indonesia. Selemba Empat. Jakarta

Zuraid, I. 2012, "teknik penyusuan Peraturan Daerah tentang Pajak Daerah dan Retribusi Daerah" Jakarta: Sinar Grafika 